\title{
Acquired double-chambered right ventricle
}

\author{
Piotr Zieliński ${ }^{1}$, Katarzyna Kożuch ${ }^{1}$, Jacek Różański ${ }^{2}$, \\ Ilona Michałowska ${ }^{3}$, Piotr Hoffman ${ }^{1}$ \\ ${ }^{1}$ Department of Congenital Heart Diseases, Institute of Cardiology, Warsaw, Poland \\ ${ }^{2}$ Department of Cardiac Surgery and Transplantology, Institute of Cardiology, Warsaw, Poland \\ ${ }^{3}$ Department of Radiology, Institute of Cardiology, Warsaw, Poland
}

The double chambered right ventricle is a rare complication following surgical closure of ventricular septal defect (VSD). Herein presented is a 53-year-old woman after surgical correction of VSD and the pulmonary stenosis in childhood. She also underwent pacemaker implantation due to third degree atrioventricular block. She was admitted to the documented clinic due to progressive exertional intolerance. Transthoracic echocardiography (TTE) discovered a large interventricular patch protruding into the right ventricle (RV) and causing a substantial or tight narrowing of the RV resulting in an intraventricular maximal pressure gradient of $110 \mathrm{mmHg}$. Also, insignificant left-to-right shunt (Fig. 1A, B) was detected.
The dimensions of the RV and the left ventricle were normal, and mild tricuspid regurgitation was demonstrated. The cardiac computed tomography confirmed a large protrusion of the patch closing VSD causing obstruction within the RV (Fig. 1C, D). The patient was referred to cardiac surgery. A large velour patch of $2.5 \times 2 \mathrm{~cm}$ diameters was excised and subsequently the intraventricular septum was reconstructed by means of part of the patch. The postoperative period was uneventful. The follow-up TTE showed (Fig. 1E, F) normal dimensions and contractility of the RV; the pressure gradient within of the RV outflow was $12 \mathrm{mmHg}$. The patient was discharged in good condition.

Conflict of interest: None declared

Address for correspondence: Dr. Ilona Michałowska, Department of Radiology, Institute of Cardiology, ul. Alpejska 42, 04-628 Warsaawa, Poland, tel: +48 2234341 68, e-mail: ilona.michalowska@ikard.pl

Received: 14.02.2019 Accepted: 23.06.2019 


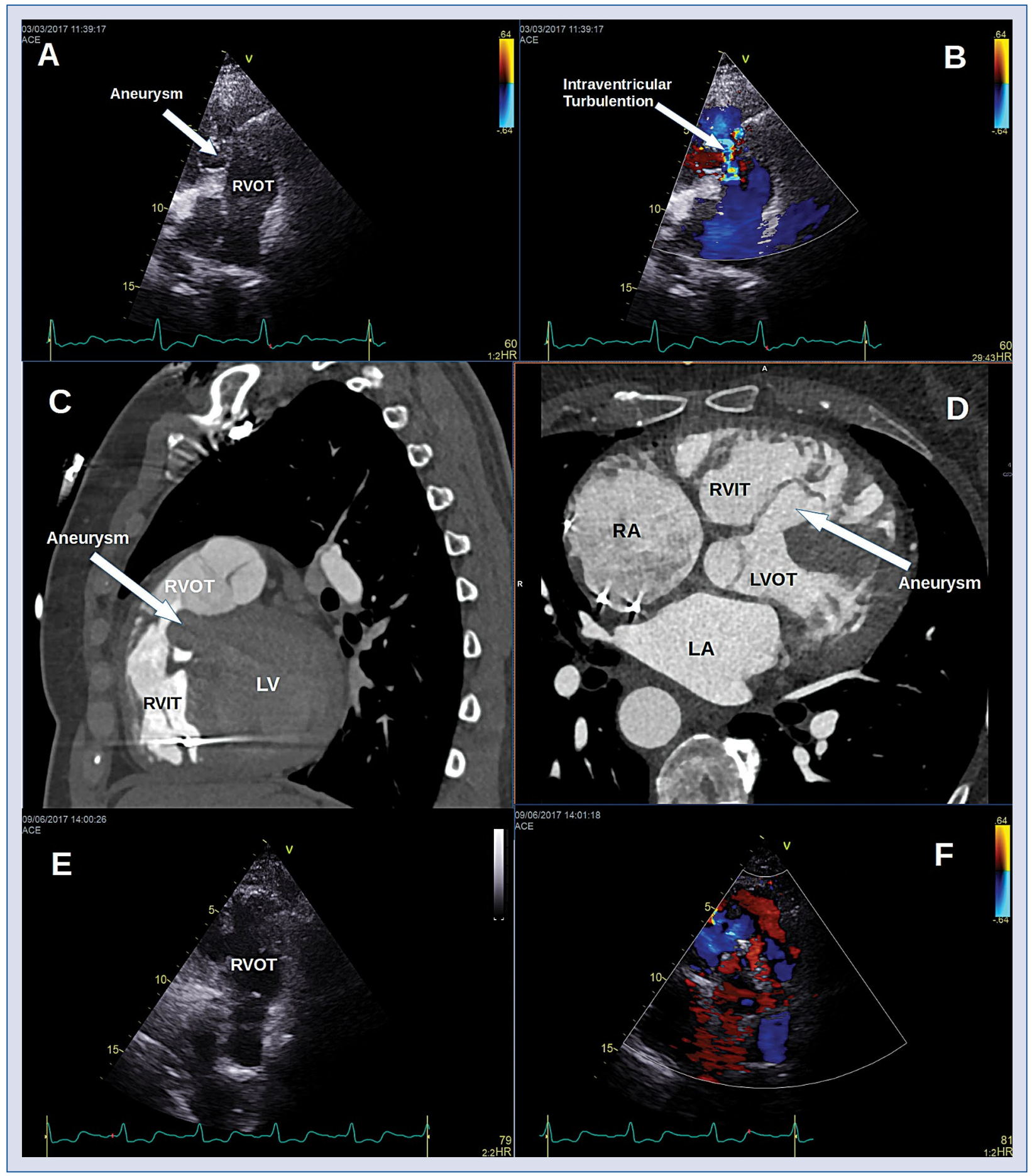

Figure 1. A, B. Transthoracic echocardiography (short axis) shows an aneurysm (arrow) and intraventricular turbulences; C, D. Cardiac computed tomography shows an aneurysm of a patch closing interventricular septal defect which is bulging into the right ventricle and causing significant stenosis of the right ventricle outflow; E, F. Transthoracic echocardiography (short axis) shows postsurgical right ventricular outflow tract (RVOT); LA — left atrium; LV — left ventricle RA — right atrium; RVIT — right ventricular inflow tract. 